\title{
What industry taught us about repeated time-related events
}

\author{
Eugene H. Blackstone, MD, a,b and Tara B. Karamlou, MD
}

\footnotetext{
From the Departments of ${ }^{\mathrm{a}}$ Thoracic and Cardiovascular Surgery, Heart and Vascular Institute, and ${ }^{\mathrm{b}}$ Quantitative Health Sciences, Research Institute, Cleveland Clinic, Cleveland, Ohio; and the ${ }^{\mathrm{c} D e p a r t m e n t ~ o f ~ T h o r a c i c ~ a n d ~}$ Cardiovascular Surgery, Phoenix Children's Heart Center, Phoenix, Ariz.

Supported by Cleveland Clinic.

Disclosures: Authors have nothing to disclose with regard to commercial support.

Received for publication Sept 25, 2017; accepted for publication Sept 27, 2017; available ahead of print Nov 7 , 2017.

Address for reprints: Eugene H. Blackstone, MD, Department of Thoracic and Cardiovascular Surgery, Cleveland

Clinic, 9500 Euclid Ave, Desk JJ-4, Cleveland, OH 44195 (E-mail: blackse@ccf.org).

J Thorac Cardiovasc Surg 2018;155:737-8

$0022-5223 / \$ 36.00$

Copyright (C) 2017 by The American Association for Thoracic Surgery

https://doi.org/10.1016/j.jtcvs.2017.09.124
}

A positive aspect of the first recall of the Braunwald-Cutter heart valve for catastrophic poppet escape was assistance from industry regarding how to assess rare device failures. General Electric statistician Wayne Nelson, $\mathrm{PhD}$, was particularly helpful in introducing us to analysis of repeated $^{1}$ and weighted events ${ }^{2}$ : repeated repairs of electric motors and cost of those repairs in his experience. Buried in General Electric technical reports, his methods were independently discovered by Aalen. ${ }^{3}$

Unlike medicine, which focuses on survival, industry focuses on the hazard function - the instantaneous risk of events. Constant hazard means "random failure"; high initial hazard means "burn-in." The hazard function, however, is inherently noisy. The area under the hazard curve - cumulative hazardmitigates this noise. Nelson's major contribution was devising a nonparametric (non-model-based) method to estimate cumulative hazard $\Lambda(t)$. Raw data are the number of events (usually 1) at time $k\left(n_{d k}\right)$ and the number of subjects (such as motors) at risk at that time $\left(n_{r k}\right)$. Cumulative hazard at any time $t_{i}$ is the sum of the ratios $n_{d k} / n_{r k}$ up to that time:

$$
\Lambda\left(t_{i}\right)=\sum_{k=1}^{i} \frac{n_{d k}}{n_{r k}} .
$$

Importantly, the number at risk is not decreased at an event's occurrence. It remains the same until a subject dies, follow-up ends, or the subject is no longer at risk (eg, has had a faulty valve replaced).

For a terminating event, such as death, the Nelson and Kaplan-Meier estimates converge to the same answer (see Appendix 1), because $\Lambda\left(t_{i}\right)=-\ln \left[S\left(t_{i}\right)\right]$, where $S\left(t_{i}\right)$ is survival at time $t_{i}$. The Kaplan-Meier method, however, which is based on probability, is limited to a single terminating event. Nelson's method has no such limitation, allowing patients-like motors - to remain under observation as subsequent events of the same nature are observed. Further, the event does not have to be binary (yes/no); it can have a value (such as cost, length of stay, ${ }^{4}$ or degree of severity of the event).

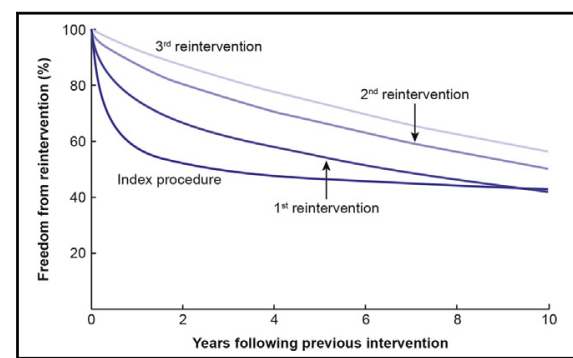

Repeated reinterventions after neonatal repair of critical aortic stenosis.

\section{Central Message}

Investigations often analyze only the first occurrence of a sequentially repeating time-related event. All these events can be analyzed, providing superior power for statistical and clinical inferences.

See Article page 726 .

The unit of cumulative hazard is events/patient. If events are infrequent, one might graph cumulative hazard as events per 100 or per 1000 patients. Similarly, cumulative cost yields quantity per patient, but this can be multiplied for quantity per 100 or 1000 patients.

But that is not all! Kalbfleish and Prentice ${ }^{5}$ introduced us to the industrial method of "modulated renewal," embodied in terms such as "good as new," "better than new," and

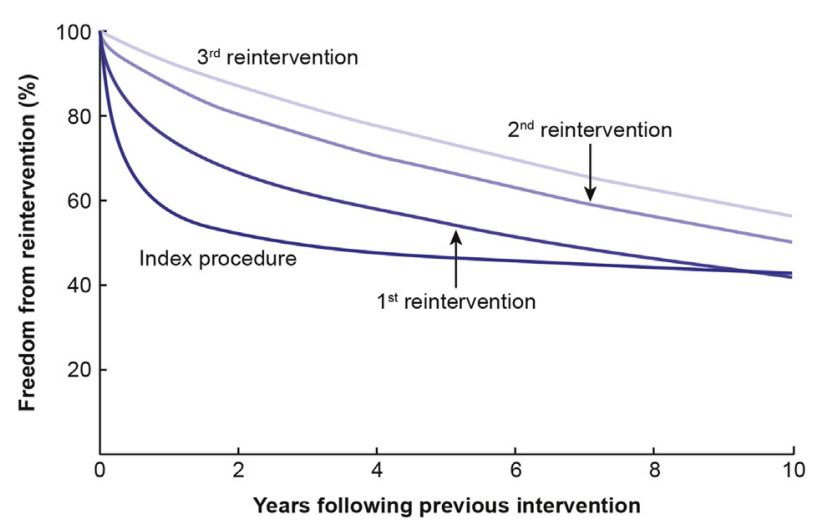

FIGURE 1. Repeated reinterventions after neonatal repair of critical aortic stenosis, ${ }^{6}$ illustrating modulated renewal analysis. The darkest curve is freedom from a first reintervention. Those experiencing a first reintervention are restarted at time zero, and the second curve is freedom from a second reintervention after having experienced a first reintervention, and so forth. Notice that after each reintervention, the likelihood of having another intervention progressively diminishes. This adds yet another dimension to clinical inferences beyond that of the Nelson repeated-events method. 


\begin{abstract}
"worse than new." One simply uses the Kaplan-Meier method to depict time to first event from time zero. Then, individuals experiencing the first event are started at that new time zero, and a Kaplan-Meier curve is drawn to depict freedom from a second event. This is repeated for each subgroup of patients experiencing recurrence of the event. Both the Nelson and modulated renewal methods have been applied to congenital heart disease (Figure 1). ${ }^{6,7}$

As we reviewed the original manuscript of Balasubramanya and colleagues' article $^{8}$ on right ventricular outflow tract reintervention after primary tetralogy of Fallot repair in this issue of the Journal, we believed they could perform a more powerful analysis using these methods that accounted for repeating events (events being the effective sample size for time-related analyses ${ }^{9}$ ). They ${ }^{8}$ took our advice and analyzed these repeated reinterventions, resulting in greater insight into their nature after repair of tetralogy of Fallot.
\end{abstract}

\section{References}

1. Nelson W. Hazard plotting for incomplete failure data. J Qual Technol. 1969;1: 27-52.

2. Nelson W. Confidence limits for recurrence data: applied to cost or number of product repairs. Technometrics. 1995;37:147-57.

3. Aalen O. Nonparametric inference for a family of counting processes. Ann Statist. 1978:6:701-26

4. Smedira NG, Hoercher KJ, Lima B, Mountis MM, Starling RC, Thuita L, et al. Unplanned hospital readmissions after HeartMate II implantation: frequency, risk factors, and impact on resource use and survival. JACC Heart Fail. 2013;1:31-9.

5. Kalbfleisch JD, Prentice RL. The Statistical Analysis of Failure Time Data. 2nd ed. New York: John Wiley \& Sons; 2002.

6. Hickey EJ, Caldarone CA, Blackstone EH, Williams WG, Yeh T Jr, Pizarro C, et al. Congenital Heart Surgeons' Society. Biventricular strategies for neonatal critical aortic stenosis: high mortality associated with early reintervention. $J$ Thorac Cardiovasc Surg. 2012;144:409-17.

7. Cook RJ, Lawless JF. Analysis of repeated events. Stat Methods Med Res. 2002; 11:141-66.
8. Balasubramanya S, Zurakowski D, Borisuk M, Kaza AK, Emani SM, del Nido PJ, et al. Right ventricular outflow tract reintervention after primary tetralogy of Fallot repair in neonates and young infants. J Thorac Cardiovasc Surg. 2018;155: 726-34.

9. Blackstone EH. Sufficient data. J Thorac Cardiovasc Surg. 2016;152:1235-6.

\section{APPENDIX 1. COMPARISON OF KAPLAN-MEIER AND NELSON ESTIMATORS}

The Kaplan-Meier estimator for survival at time $t_{i}, S\left(t_{i}\right)$, is as follows:

$$
S\left(t_{i}\right)=\prod_{k=1}^{i}\left(1-\frac{n_{d k}}{n_{r k}}\right)
$$

where $n_{d k}$ is the number of terminating events at time $t_{k}, n_{r k}$ is the number remaining at risk, and $\Pi$ means to multiply the kth term by the preceding product.

Cumulative hazard is the negative natural logarithm (ln) of $S\left(t_{i}\right)$ (remembering that logarithms turn products into sums), where $\Sigma$ means to add the kth term to the preceding sum:

$$
\Lambda\left(t_{i}\right)=\sum_{k=1}^{i} \ln \left(1-\frac{n_{d k}}{n_{r k}}\right) .
$$

To convince you that $\ln \left(1-n_{d k} / n_{r k}\right)$ is nearly the same as $n_{d k} / n_{r k}$, which Nelson's method uses, if $n_{r k}=100$ and $n_{d k}=1$, then $1-n_{d k} / n_{r k}=0.99$, and its natural logarithm is 0.01005 . Compare this with the Nelson estimate of $n_{d k} / n_{r k}=1 / 100=0.01$. For all practical purposes, they are equivalent (and much easier to calculate than using logarithms!). 